\title{
“A BICHA DA PELE MAIS FINA": CONFLUÊNCIAS ENTRE GÊNERO E A FORMAÇÃO VOCAL DO ATOR
}

RESUMO

Na escrita deste ensaio compartilho minha experiência como docente substituta na Universidade Federal de Uberlândia, ministrando a disciplina de Consciência Vocal, no primeiro semestre de 2017. Relato o encontro com um estudante em específico e os desafios e memórias que o mesmo desdobra. Problematizo, a partir da narrativa desta experiência, as questões de gênero e a formação vocal do ator

Palavras-chave:

Gênero. Voz. Formação do ator. 


\section{"A bicha da pele mais fina": confluências entre gênero e a formação vocal do ator ${ }^{1}$}

\footnotetext{
${ }^{1}$ Ensaio produzido para a disciplina Corpo, Gênero e Sexualidade na História do Teatro Brasileiro, conduzida pelo Prof. Dr. Ferdinando Martins, no PPGAC, da ECA/USP, e dedicado a meu aluno Whander Allípio.

${ }^{2}$ Professora substituta na UFU e doutoranda na USP/ECA. E-mails para contato: mariaclaudialopes9@hotmail.com e marialyra9@yahoo.com.br.
}

Maria Lyra (Maria Cláudia S. Lopes)²

Em minha trajetória pessoal reconheço um espaço considerável em que experimentei a voz e o canto cotidianamente. Na infância em escolas de música e coral, no teatro através de processos nos quais tomei parte como atriz, e depois no Grupo de Pesquisa Sobre Práticas e Poéticas Vocais, no qual investigamos, entre 2010-2015, o limiar entre fala e canto, praticando canções em grupo. Neste espaço, a canção era vista como possível disparadora da criação dramatúrgica e da exploração da potencialidade poética da voz no trabalho do ator.

O canto e a voz poética sempre estiveram presentes em meu percurso - pois somos seres cantantes. Ainda que o canto e a voz sejam delegados, infelizmente, aos cantores, sabemos que há espaços em que o canto é mantido como prática de todos e como expressão do ser ligado ao cotidiano e à cultura, um espaço cultivado e fundamental. Neste sentido, acredito que porque a palavra tenha se tornado, em um contexto amplo, mero "utensílio de barganha" (NOVARINA, 2009), e, porque parecemos nos distanciar da "voz poderosa", vejo a possibilidade de trabalhar como professora das disciplinas de voz como uma oportunidade para fazer política através da poiesis, devolver ao uso comum aquilo que é tão valioso e nosso, o exercício da voz poética e o reconhecimento da voz como manifestação do ser.

O nome dele é Whander, Whander Allípio, e é sobre ela que decido escrever este ensaio. Meu aluno da "pele mais fina", que me fez pensar e repensar sobre o quanto a nossa perspectiva cultural de gênero nos influencia enquanto docentes no trabalho de formação de atores. O nome dela é Whander e ela tem 17 anos, é cristã, homossexual, negro, efeminada e se considera de gênero não-binário - termo que até nosso encontro eu nunca ouvira. Um corpo negro e masculino/feminino, com gestualidades e vocalidade (timbre, melodia, acento) "femininos". Um corpo que se desafiou com muita dor a transgredir alguns limites, sentindo-se aviltado por relacionar seu corpovoz à sua identidade, duramente construída. Penso e repenso sobre os limites entre estimular o ator na busca de um repertório amplo em sua capacidade expressiva e a aceitação de novos modos de ver/entender corpo e gênero para os quais sinto que talvez não estejamos (universidade/cursos de teatro) preparados. 
Minha trajetória como docente substituta no curso de Teatro, da Universidade Federal de Uberlândia, começou no primeiro semestre de 2016. No segundo semestre deste mesmo ano ministrei a disciplina de Consciência Vocal para o primeiro período. Gosto particularmente dos primeiros períodos, os estudantes me parecem mais abertos e encantados com todas as novidades que a entrada no curso lhes apresenta. Minha pesquisa como graduanda, mestranda e agora doutoranda esteve sempre relacionada à voz, ao corpo voz, ao canto e à qualidade de presença do ator. Trabalhamos ao longo do semestre a partir do entendimento de que voz e corpo estão integrados; conhecer as qualidades vocais individuais para ampliar o repertório e a capacidade expressiva da emissão do som estão entre os principais objetivos da disciplina. A voz é, primeiramente, trazida para íntimo diálogo (respiração, ritmo, escuta), e então experimenta-se sua dimensão lúdica e poética, as suas possibilidades elásticas e estéticas. Os elementos de musicalidade da cena são introduzidos, possibilitando ao estudante uma segurança maior no improviso em processos futuros de criação. A palavra é trabalhada em seu aspecto material, em sua concretude sonora, como corpo sonoro, não apenas se restringindo à relação de signo-significante. Os encontros são práticos, e neles trabalhamos a sensibilização, o exercício da voz poética, convergindo para uma experiência com o público ao final do semestre, a partir do trabalho com partituras corpovocais.

Como qualquer estudante em sua primeira aula, chegamos inseguros do que iremos encontrar lá, experiências que talvez não pensamos que vamos viver dentro de um espaço acadêmico. O que entendemos por consciência vocal, durante o tempo que iremos ter esse semestre, pode ser modificado, construído, moldável e poderemos descobrir inúmeras verdades sobre essa voz que nos completa e nos representa como pessoa. Fomos convidados a nos conectar no espaço/tempo, ou seja, no aqui e agora, para que pudéssemos estar bem e concentrados para a aula. Algo que me chamou atenção foi a relação com o quanto de céu tem sobre nossas cabeças e o quanto de terra tem sob nossos pés, esta linha que passa pelo corpo. As canções que nos foram apresentadas no primeiro dia foi algo inédito, algo que eu não conhecia e que fez com que eu tivesse um entusiasmo grande sobre a disciplina (Whander Allípio. Diário de Voz. Março/2017).

Os encontros se estruturavam em três partes: no momento de chegada havia o trabalho de sensibilização da escuta, relaxamento da laringe, consciência sobre a respiração e o uso de vogais, transformando o ar na emissão de som; o segundo momento consistia em exploração lúdica da voz e possibilidades sonoras a partir de jogos coletivos ou em dupla, ou ainda, experimentação de ações vocais a partir de verbos (torcer, flutuar, quebrar, deslizar), trabalhando individual e simultaneamente a diversidade expressiva da palavra através de fragmentos de textos ou letras de canções. Em um último momento explorávamos composições de sequências de movimentos individualmente ou em subgrupos, encerrando o encontro com roda de partilha sobre a experiência em cada aula.

O bocejo, mesmo que falso, foi novo para mim, e como ele realmente ajuda e faz diferença. Após começarmos a nos movimentar no espaço, fazendo movimentos (algo que eu já gosto muito), e minha dinâmica me remeter a uma dança indiana, um fluxo preciso, porém um pouco mais leve, algo que eu acho bonito seja fazendo ou vendo, me trouxe na memória o começo do meu contato com a arte. Além dos cânticos singulares que aprendemos durante a aula, fizemos um exercício que, creio eu, de grande valia para meu crescimento como artista: o trabalho das vogais pelo corpo e o depois a repetição do mesmo porém com movimentos. O que me agrada muito, pois gosto dessa liberdade que temos de criação com os movimentos que são gerados a partir dessa voz que desce pelo meu corpo, a intensidade, a altura, a velocidade e como tudo isso se altera em 
nossos movimentos, algo que talvez eu nunca havia parado para pensar e que agora reflito sobre. (Whander Allípio. Diário de Voz. Abril/2017).

O uso de algumas imagens, como a ideia do som que desce e se enraíza - em oposição à ideia do som que é projetado - ou a ideia das caixas de ressonância, eram experimentados semanalmente. Jogos em que se vivenciavam direção, velocidade, intensidade e altura. Ao final do encontro, compartilhávamos os momentos mais interessantes uns com os outros e construíamos juntos uma reflexão sobre o encontro em roda de conversa ou a partir de registros (desenhos) sobre as sensações/percepções de cada aula. Os estudantes cultivaram, ao longo da disciplina, um espaço de registro reflexivo individual que poderia ser escrito ou falado (gravação em áudio) e que depois foi entregue como procedimento de avaliação da disciplina.

Meu nome é Whander Allípio, tenho 17 anos, sou cristã, homossexual, preta, efeminada e minha identidade de gênero é não-binário, por isso muitas vezes posso usar tanto o feminino como o masculino, pois me sinto bem com os dois. Sou amante da indumentária, que conta muito sobre cada pessoa, suas diversas personalidades e como se colocam no mundo, arte que admiro bastante. Desde muito pequeno fui apresentado à arte; o meu primeiro contato foi a dança com minha família, depois o teatro na igreja e na escola, o que me fez querer e sonhar com Artes Cênicas, iria envolver tudo que eu gosto relacionado à cena, inclusive performance, algo que eu amo (Whander Allípio. Diário de voz. 10/03/2017).

Cada estudante/ser é um universo muito particular, são muitos deles e a escuta que tenta se equilibrar entre coletiva e singular nem sempre capta as nuances da experiência subjetiva de cada um. Corpos silenciosos na escuta de si, corpos em movimento, corpos em relação entre corpos e espaço, corpos vocais desenhando-se no espaço e conhecendo seus limites. Observava, como professora, de um lado, a profundida que a auto percepção poderia alcançar, e, de outro, o encontro entre estudantes e a capacidade expressiva de seus corpos vocais em suas variações. Até onde meu campo de visão alcançava percebia em Whander uma voz que oscilava entre timidez/retraimento e a autoafirmação de sua identidade "bicha, preta, cristã, efeminada, de gênero não-binário, de 17 anos”. Como mulher, 35 anos, homossexual, branca, que já viveu fases em que se sentiu mais masculina e casada com outra mulher, me identificava e compreendia a importância de defender a própria identidade diante de uma sociedade que nega a diferença. Como professora, me preocupava com o que entendia como uma entrega restrita para se experimentar como outros, experimentar-se corporal e vocalmente de outras maneiras. Falo de qualidades distintas de movimento e registros vocais variados, falo da elasticidade da voz e do que ela é capaz de fazer sem que isso signifique a perda da identidade ou a autonegação. O que chamava atenção era de um lado o que eu entendia como limite/limitação e que poderia prejudicar a (trans)formação do estudante e de outro, respeito por sua identidade e a dúvida de até que ponto a minha preocupação não estava relacionada a uma dificuldade de lidar com outro corpo, diverso e binário. Seria a capacidade desse corpo diverso de transitar realmente entre alto e baixo, assim como agudo e grave, de fato um sinal de avanço?

"Vira mulher!" foi a frase que eu ouvi no processo de montagem de espetáculo amador ao fazer a personagem da gata, em Os Saltimbancos. Eu, uma menina de 14 anos, desconfortável no corpo e em dúvida sobre minha sexualidade. Confusa e misturada entre a noção de gênero e sexualidade; vestindo camisetas largas, bonés e sapatos que me minha mãe dizia ser de homem. "Travada para andar como uma mulher, usar saltos como mulher, ser feminina, sensual, delicada e vaidosa como mulher na vida e em cena". Observava os corpos que eu julgava realmente femininos, performava, observava o movimento felino e timidamente conseguia também performá-lo no corpo. "Vira mulher" - quando ouvi essa frase no ensaio foi um momento de violência, mas compreendi que a diretora se referia a certas qualidades de movimento que no cotidiano não me vinham com facilidade, mas essa expressão já permeava os interiores do meu castelo, escola, casa e pensamentos. No fim do processo eu reconheci a importância de encontrar em mim aquelas 
outras qualidades, e percebi que estavam no meu interior como possibilidades minhas, que me orgulhava de poder reconhecê-las como outras de mim mulher/ atriz.

Mas como seria questionar um sistema epistemológico/ontológico? Qual a melhor maneira de problematizar as categorias de gênero que sustentam a hierarquia dos gêneros e heterossexualiade compulsória?[...] O próprio sujeito das mulheres não é mais compreendido em termos estáveis ou permanentes. É significativa a quantidade de material ensaístico que não só questiona a viabilidade do 'sujeito' como candidato último à representação, ou mesmo à libertação, como indica que é muito pequena, afinal, a concordância quanto ao que constitui, ou deveria constituir, a categoria mulheres (BUTLER, 2003, p. 9).

Judith Butler ${ }^{3}$ afirma que o gênero é performativo, não apenas performado, como um papel em que atuamos. Sendo performativo, ele produz uma série de efeitos/impressões fora de nós. Andamos e falamos de formas que consolidam uma impressão de sermos mulheres ou homens. A teórica diz que ninguém é, realmente, um gênero, que apesar de agirmos como se ser homem/mulher fosse uma realidade interna ou um fato, ser um ou outro é, na verdade, um "fenômeno que é produzido e reproduzido". Butler aponta para a dificuldade que existe para determinados sujeitos de se relacionarem socialmente sem sofrer ameaças, e afirma que há poderes institucionais, como segmentos da psiquiatria, por exemplo, bem como práticas informais, como bullying, que tentam nos manter no gênero adequado, certas normas de gêneros são estabelecidas e policiadas, portanto Butler se pergunta sobre qual seria a melhor forma de subvertê-las.

\footnotetext{
${ }^{3}$ Segundo fala apresentada no I Seminário Queer - Cultura e Subversão das Identidades - 9 e 10 de setembro/2015, no Sesc Vila Mariana, em São Paulo.
}

O meu ser feminino é forte e muito presente, então eu tenho que provar pra mim mesmo e para as pessoas que eu sou mais que uma bicha escandalosa, e sou muito mais que isso. Neste curso, desde que eu entrei, parece que isso é um problema, porém, essa bicha nunca vai morrer, porque eu sou ela, essa busca pelo "tônus" me deixa abalada, porque parece que eu não consigo fazer isso, mas tenho que mostrar que sou capaz e que esse tipo de coisa não vai me abalar

(Whander Allípio. Diário de Voz. Março/2017).

Na experiência de Whander, a questão de gênero me parecia delicada, pois mesmo cursando uma graduação em teatro - contexto em que a sexualidade é vivenciada de forma mais diversa e aberta -, em seus depoimentos e diário de voz parecia haver uma tensão dolorosa provocada pelos apontamentos que ouvia de mim e de outros professores, sobre "precisar de mais tônus", "engrossar a voz" (sua narrativa). Parecia haver uma "atitude de resistência" - inconsciente, talvez, - diante de algumas observações que eu fazia sobre experimentar outros registros vocais.

Judith Butler (2015) nos fala sobre a importância de resistir à violência, especialmente a violência praticada contra aqueles que ela chama de pessoas non-conforming ["não conformadas"] em seu "lugar de gênero dado". Questiono-me, portanto, sobre o respeito a nossos alunos resistentes, que rompem com o paradigma do binarismo e da heterossexualidade compulsória e machista. Questiono-me sobre nossa falta de preparação para lidar com corpos em formação que realmente se apresentem a partir de novas identidades, identidades essas que para nós talvez ainda pareçam muito complexas pela educação que recebemos.

Escrevemos em uma folha as experiências, as memórias e tudo que fomos trabalhando durante a disciplina. Isso me fez questionar muito, pois minhas palavras foram: WHANDER, SALTO, SENSAÇÕES, ROSA, BICHA, PRECONCEITO, NÃO-BINÁRIO, VITÓRIA, FINA, MÃE, ALEGRIA, LIBERTAÇÃO, MUNDO, FAMÍLIA E LUTA (Whander Allípio. Diário de Voz. Março/2017). 
Não me é tão estranho pensar em como as "bichas" pareciam se segregar e se dividir em categorias pelo "grau de homossexualidade". Meus amigos, gays como eu, homens e mulheres, também pareciam confundir orientação sexual e gênero. "Gosto de homem", diziam alguns amigos, "por isso não gosto de veado afeminado, se for pra ficar com bichinha eu fico com mulher de uma vez" ou "eu sou lésbica, mas não sou caminhoneira, sou sandalinha e não sapatão, sou lésbica, mas sou feminina", eu ouvi muitas vezes, como se existisse um limite adequado para ser gay e aqueles mais conformados em seu gênero "de origem" estivessem num lugar melhor. Uma separação entre gays e veadinhos. "Filho, tudo bem você ser veado, mas não se vista de mulher", um amigo ouviu de sua mãe. Assim também, na minha experiência de teatro amador, desde a primeira oficina que fiz, diferentes professores e encenadores em processos distintos de criação/montagem se incomodavam se um ator - especialmente do sexo masculino - não conseguisse explorar outros trejeitos, menos efeminados, em momentos exigidos pela cena. Lembro-me instantaneamente do filme A Bela do Palco, direção de Richard Eyre (2004), que narra o quanto a mudança legislativa, envolvendo a permissão para que mulheres pudessem atuar em cena, marca a vida dos atores treinados para representar personagens femininos. Seria o nosso momento um novo contexto histórico em que pela resistência e luta pelo direito à subversão dos gêneros impostos teríamos que, como docentes, repensar também a nossa prática em relação à formação vocal dos atores?

Foi a melhor aula de consciência vocal até agora, me senti muito confortável fazendo. Primeiramente, tivemos que escolher um fragmento de texto de nosso gosto para levar para aula, procurei algo que fosse forte e que ao mesmo tempo mostrasse quem eu sou. Escolhi o fragmento da música "A pele mais fina", da banda Salada de Frutas": "Vou ser a bicha da pele mais fina com minhas amigas vou me embelezar/Vou ser a bicha da pele mais fina com minhas amigas

\footnotetext{
4 Disponível em: <https://www.youtube.com/watch?$\mathrm{v}=7 \mathrm{KyTViP} 3 \mathrm{SEQ}>$.

${ }^{5}$ https://www.youtube.com/watch?v=mSKC8cGw7XU
}

vou me embriagar/ Bota o salto e vou pro mundo nessa corda bamba sambar [...]". Essa foi minha escolha; ao escutar pela primeira vez esta música senti que ela foi escrita para mim, estava passando por um momento delicado, e ela representa como eu me coloco diante do mundo, dando a cara para bater, sambando nessa corda bamba que nunca sabemos quando vai arrebentar, sem se preocupar com o que o outro pensa ou não, simplesmente sendo eu (Whander Allípio. Diário de voz. Março/2017).

Como pesquisadora do campo da voz, dentro da área de teatro, tenho um posicionamento muito distinto daquele relacionado à perspectiva tecnicista da formação do ator e do ensino universitário. Do ponto de vista ideológico, isto significa que não acredito que os cursos de formação sirvam necessariamente e somente ao intuito de preparar para o mercado de trabalho. Se existe uma função social das artes e da universidade na sociedade, para mim, como também afirma Judith Butler (informação oral ${ }^{5}$, entrevista dada em Belgrano, 2015), esta função está associada à reflexão, ao questionamento crítico e às ações que caminham no sentido de transformação da sociedade, mais do que à boa manutenção da mesma. Portanto, uma formação artística universitária apropriada, a meu ver, caminharia menos em direção à ideia de domínio de saberes e habilidades posteriormente aplicáveis mais no sentido de reconhecimento do ser em suas múltiplas dimensões, o alinhamento entre sua ética e sua estética a partir de quem se é. Neste sentido, comentários como "você não tem corpo/voz para teatro", "não sei cantar, não tenho voz, não sei respirar", “a minha voz é feia, é inadequada, não gosto dela", sinalizam muito mais a necessidade de reconhecimento, consciência e potencialização da voz que já é, do que o aprimoramento técnico, como algo que se apreende de fora para dentro ou que se adquire.

Sugeri, como parte da finalização da disciplina, a construção de uma partitura corpo vocal que explorasse sonoridades e fragmentos do texto com que já estavam trabalhando. Whander, 17 anos, homossexual, negra, não-binário e cristã, escolheu um fragmento relacionado à representação de sua identidade, a letra da música "De pele mais fina", cantada 
por uma banda cujos sujeitos também subvertem as categorias clássicas do gênero. Sua composição, desde a escolha dos movimentos, ações e acessórios, me parecia figurativa, porque reforçava as palavras ditas. Do ponto de vista estético, após assistir, meu comentário trazia a importância do contraste de sentidos, e, como professora de voz, apontava para a necessidade de explorar variações de altura, velocidade, timbre e procurar outras formas de dizer o texto.

Depois de todas as apresentações da turma comentamos as partituras. Nesse momento, veio a mim: "Que eu deveria tentar outra voz, para buscar melhores qualidades de um exercício", não foi exatamente com essas palavras, mas foi mais ou menos isso, o que me destruiu por completo. Eu saí de dentro da sala quase chorando, porém não consegui derramar uma lágrima se quer. Falava para mim mesma: "Por que eu? Por que eu tenho que engrossar voz? Por que eu? O meu lugar não é aqui, eu tinha que ter ido para Artes Cênicas, onde a dança-teatral e a performance são mais presente do que aqui. Essa é minha voz, tenho que mudar minha partitura inteira?", Felipe foi me consolar e tentar me explicar melhor o que a professora queria dizer. $O$ fato é que, durante a semana, eu já estava exausta com essa situação de ter que provar para mim mesma que eu sou mais do que isso que as pessoas veem. (Whander Allípio. Diário de voz. Março/2017).

Eu queria poder dizer a ele que ele havia me entendido mal. Que eu também sou gay, sou artista, me considero uma professora sensivel e respeitosa em relação à diversidade. Dizer que ele não precisava provar ser nada além do que era, que eu só quis sugerir que ele experimentasse outras nuances de movimento e de registros vocais, que isso não interferiria em quem ele era, em como se sentia no mundo. Dizer que, para o ator, talvez, fosse importante pensar em outras possibilidades de ser, de ser outros sendo a gente mesmo. Perguntei-me por que razão ele recebeu meus comentários de forma tão intensa e por que eu o havia ferido tão profundamente. Em seu exercício final, no último dia de avaliação da disciplina, eu o vi experimentar outros movimentos, criando contrastes entre altura da voz (graves) e movimentos mais duros e pontuados, deslocamentos em linha, pausas e na roda final de conversa ela se emocionou e me pediu que eu a abraçasse. Nas últimas linhas do diário me agradeceu por permitir que ele "provasse ser mais que uma bicha escandalosa".

A escrita final que apreciei como procedimento metodológico de avaliação me causou certo rebuliço. Se de um lado eu me sentia satisfeita pelos agradecimentos que ouvi e li, eles me pareciam inadequados. Meu objetivo não era sugerir que o estudante provasse nada relacionado a seu ser ou identidade. No entanto, foi essa a leitura de Whander sobre o que ele/ela precisaria fazer para se desenvolver enquanto ator/atriz.

Judith Butler (2003, p.24) pontua ser o gênero, não um substantivo ou atributos flutuantes, mas fenômeno da "performatividade" produzido e imposto pelas práticas reguladoras da coerência do gênero. O gênero é "um feito", mesmo preexistindo o sujeito que o faz, "não há identidade de gênero por trás das expressões do gênero, essa identidade é performativamente constituída, pelas próprias expressões tidas como seus resultados".

A experiência na disciplina de encontro com a diferença "resistente" de Whander me fez, verdadeiramente, rever alguns parâmetros de observação, rever perspectivas relacionadas à formação vocal do ator, questionar o nosso sistema de ensino e a possibilidade de ele não estar preparado para lidar com corpos que não negam a sua diferença. Qual é a medida entre respeito e provocação, se a pele é fina? Pergunta para ser levada a sério. 


\section{REFERÊNCIAS}

ALEIXO, Fernando M. Corporeidade da voz: voz do ator. Campinas: Editora Komedi, 2007.

Reflexões sobre aspectos pedagógicos relacionados ao trabalho vocal do ator. In: Moringa. João Pessoa. Vol 1, n.1, 103-116. 4/ jan./ 2010.

BUTLER, Judith P. Problemas de gênero: feminismo e subversão da identidade. Rio de Janeiro: Civilização Brasileira, 2003.

BERENDT, Joachim-Ernest. Nada Brahma: a música e o universo da consciência. São Paulo: Ed.Cultrix, 1993.

BONDÍA, Jorge Larrosa. Notas sobre a experiência e o saber de experiência. Revista Brasileira de Educação. Jan./Fev./Mar./Abr. 2002, p.20-28.

CAMPO, Giuliano. Trabalho de Voz e Corpo de Zymunt Molik - o legado de Grotowski. São Paulo: Realizações Editora, Livraria e Distribuidora, 2012.

MACHADO, Marina Marcondes. O "Diário de Bordo" como ferramenta fenomenológica para o pesquisador em Artes Cênicas. Sala Preta (USP), v. 2, p. 260-263, 2002.

MARTINS, José Batista Dal Farra. Percursos poéticos da voz. In: Sala Preta. Dossiê Voz, vol. 7, p. 9-16, 2007.

MENCARELLI, Fernando Antonio. Mapas e Caminhos: práticas corpóreas e transculturalidade. Porto Alegre: Revista Brasileira de Estudos da Presença, v.3, n.1, 2013.

NOVARINA, Valère. Diante da palavra. Rio de Janeiro: 7letras, 2009. 


\section{Abstract}

In writing this essay, I share my experience as a substitute teacher at the Federal University of Uberlândia, teaching the Vocal Consciousness course, in the first semester of 2017. I report the encounter with a specific student, the challenges and memories that it unfolds. From the narrative of this experience, I problematize the questions of gender and the vocal formation of the actor.

\section{KeYWORDS}

Gender. Voice. Formation of the actor. 